\title{
A New Synbiotic Consisting of Lactobacillus casei subsp. casei and Dextran Improves Milk Production in Holstein Dairy Cows
}

\author{
Kenji YASUDA $^{1)}$, Shinnosuke HASHIKAWA ${ }^{1)}$, Hiromi SAKAMOTO ${ }^{1)}$, Yuichi TOMITA ${ }^{1)}$, Sanae SHIBATA ${ }^{2)}$ and \\ Tsuneo FUKATA ${ }^{2) *}$ \\ ${ }^{1)}$ The Nagoya Research Laboratory, Meito Sangyo Co., Ltd., 25-5 Kaechi Nishibiwajima, Kiyosu, Aichi 452-0067 and ${ }^{2)}$ Gifu University \\ Veterinary Medical Teaching Hospital, Faculty of Applied Biological Sciences, Gifu University, 1-1 Yanagido, Gifu 501-1193 Japan
}

(Received 23 June 2006/Accepted 20 October 2006)

ABSTRACT. To evaluate the effects of a new synbiotic consisting of Lactobacillus casei subsp. casei (Lcc) and dextran (Dex) on milk production, a total of 58 Holstein dairy cows, which became pregnant and gave birth to calves at regular intervals and lactated steadily and continuously, were selected. The study had a completely randomized design, and the animals were divided into two groups. Group A was fed with a basic diet only, and Group B was fed with a basic diet supplemented with the synbiotic consisting of freeze-dried Lcc and mixed feed containing Dex for one year from August 2004. After supplementation with the synbiotic, milk yields and components of Group B were compared with those of Group A in the August, December of 2004, April and August of 2005. Milk yields of Group B were greater than those of Group A. There were significant differences $(p<0.01$ or 0.05$)$ between these groups for all values. Furthermore, total amounts of fat, protein and solid non-fat in Group B significantly increased in comparison with those of Group A. In addition, the somatic cell counts of Group A significantly increased in August of 2004 and 2005 in comparison with those of Group B. Thus, the new synbiotic consisting of Lcc and Dex can increase the milk production of Holstein dairy cows throughout the year. KEY WORDS: cattle, milk, synbiotic.

Recently, probiotics $[2,3,5,10,16,21,23]$ and prebiotics [4] have gained attention for their role in controlling infectious diseases and improving productive performance in calves. Generally, lactic acid bacteria are well known probiotics and are used as growth promoters to prevent intestinal infections by pathogenic bacteria, decrease stress, and stimulate host immune response [7]. On the other hand, nondigestible food ingredients are called prebiotics, and these enhance growth of lactic acid bacteria in the host intestine [8]. For example, fructooligosaccharide, xylooligosaccharide, galactooligosaccharide and dextran (Dex) are widely known and commercially available. In particular, Dex, which is a glucose polymer and well known as a plasma expander, has recently been under investigation as a prebiotic. Dex is not digested by the gastric juices and in the calf rumen, so that unaltered Dex is thought to reach the intestine and promote the growth of lactic acid bacteria in this organ. More specifically, it has been reported that when Dex is mixed into feed it improves milk production in Holstein dairy cows during hot and humid seasons in Japan [22] inhibits Salmonella contamination [6] and prevents diarrhea while increasing weight gain in calves [17].

Furthermore, the new concept of "synbiotics" is gaining acceptance. This refers to a combination of live bacteria (probiotics) and their specific substrate (prebiotics) [8]. It was reported that Lactobacillus casei subsp. casei JCM $1134^{\mathrm{T}}$ (Lcc) uniquely and specifically utilizes Dex, and that a new synbiotic of Lcc in conjunction with Dex enhances

\footnotetext{
* Correspondence to: Dr. FuKata, T., Gifu University Veterinary Medical Teaching Hospital, Faculty of Applied Biological Sciences, Gifu University, 1-1 Yanagido, Gifu 501-1193 Japan.
}

humoral and cell-mediated immune responses in mice [13, 14] and chickens [15].

The purpose of this study was to evaluate whether the new synbiotic, probiotic Lcc, and its prebiotic Dex in combination, consistently improved milk production in Holstein dairy cows throughout the year.

The experiment was carried out at a stock farm in Gifu Pref., Japan from July 2004 to August 2005. For this study, 58 Holstein dairy cows that continuously produced milk for no less than three months after delivery in July 2004 and which became pregnant and gave birth to calves at regular intervals and lactated steadily and continuously were selected in order to minimize the effects of differences in the lactation phase. They were divided into two groups. Group A (28 cows) were fed a basic diet only and Group B (30 cows) were fed the basic diet supplemented with the synbiotic consisting of freeze-dried Lcc combined with mixed feed containing Dex. For Groups A and B respectively, weights were $678.4 \pm 15.4 \mathrm{~kg}$ and $680.3 \pm 3.6 \mathrm{~kg}$; ages 62.6 \pm 5.1 months and $55.3 \pm 2.8$ months; parturition $3.0 \pm 0.3$ times and $3.2 \pm 0.2$ times (Table 1). Data were expressed as mean \pm standard error of means. Both groups were fed a

Table 1. The number of cows and their weights, ages and parturitions

\begin{tabular}{ccc}
\hline & \multicolumn{2}{c}{ Group } \\
\cline { 2 - 3 } Group & $\mathrm{A}$ & $\mathrm{B}$ \\
\hline The number of cows & 28 & 30 \\
Weight(kg) & $678.4 \pm 15.4$ & $680.3 \pm 3.6$ \\
Age(months) & $62.6 \pm 5.1$ & $55.3 \pm 2.8$ \\
Parturition(times) & $3.0 \pm 0.3$ & $3.2 \pm 0.2$ \\
\hline
\end{tabular}


Table 2. Feeding periods and kinds of feed

\begin{tabular}{ccc}
\hline & \multicolumn{3}{c}{ Period } \\
\cline { 2 - 3 } Group & Jul.2004 & $\sim$ \\
\hline A & & Aug. 2005 \\
B & Supplemented freeze-dried Lactobacillus casei subsp. casei JCM $1134^{\mathrm{T}}$ and dextran \\
\hline
\end{tabular}

basic diet of $5.0 \mathrm{~kg}$ timothy grass, $7.0 \mathrm{~kg}$ lucerne grass and $10.0 \mathrm{~kg}$ complete mixed ration, and Group B only was fed the basic diet supplemented with freeze-dried Lcc $1.0 \times 10^{7}$ CFU (colony forming unit) $/ \mathrm{kg}$ diet and a mixed feed containing 5\% Dex (Meito Healthy Friend ${ }^{\mathrm{R}}-\mathrm{Y}$ : Meito Sangyo Co., Ltd, Aichi) at a dosage of $10 \mathrm{~g} / \mathrm{head} /$ day. Milk yields and its components were measured twice each day in July, August, and December of 2004 and April and August of 2005 (at start, and one, five, nine and thirteen months after supplementation with the synbiotic) (Table 2) and the values for Group A and Group B were compared. When cows gave birth to calves during the test period after August 2004, data on milk yield and components of the cows up to three months after delivery were excluded.

Milk yields were measured with a Tru-Test Milk Meter (TRU-TEST, Auckland, New Zealand). Milk components (fat, protein, solid non-fat and somatic cells) were measured with a CombiFoss 6000 (Fujihira Industry Co., Ltd, Tokyo). Statistical differences between Groups A and B were determined using Microsoft Excel (Microsoft-Japan, Tokyo) and Statcel (OMS, Saitama), and the t-test or the Mann-Whitney $\mathrm{U}$ test depending on the distribution pattern of the data.

Milk yields of Group B were increased after supplementation with the synbiotic, and were continuously maintained at a high level. There were significant differences $(p<0.01$ or $p<0.05$ ) in the data collected for Groups A and B (Fig. 1A). It is noteworthy that the milk yields for Group A underwent the usual seasonal changes. In particular, the figures for August 2004 and August 2005 decreased remarkably.

In terms of milk components, these were present in higher amounts in Group B than in Group A (Fig. 1B-D). The amount of total fat in the milk of group B was significantly higher than for Group A in August of $2005(p<0.05)$. Total protein and solid non-fat in Group B were significantly higher than in Group A during the test period except for April $2005(p<0.01$ or $p<0.05)$. In addition, the somatic cell counts of Group A significantly increased in August of 2004 and April of 2005 in comparison with those of Group B, and those of Group A were higher than those of Group B in August of 2005, but the difference was not significant (Fig. 1E).

It has been observed that the milk production of dairy cows decreases markedly due to the effects of heat and humidity stress $[12,20]$. However, we previously reported that this mixed feed containing Dex could improve milk production in Holstein dairy cows by decreasing stress during summer in Japan when it is particularly hot and humid [22]. It was also shown that Dex was useful as a prebiotic in decreasing heat and humidity stress. However, theoretically, if only prebiotics are administered into the intestine, there are no effects in the absence of beneficial bacteria capable of utilizing the prebiotics. Conversely, if only probiotics are administered into the intestine, this creates competition for nutrients with other bacteria. It is obvious that prebiotics and probiotics are interdependent. Accordingly, we investigated what kind of beneficial bacteria acting as probiotics could utilize Dex, and found that Lcc could uniquely utilize Dex. Furthermore, the unique and specific combination of Lcc and Dex as a synbiotic had oral immuno-adjuvant activity in mice $[13,14]$ and laying chickens [15]. When Lcc was orally administered with Dex to the mice, Lcc was specifically detected in the intestine and total lactobacilli in the intestinal microflora were significantly increased. This showed that by utilizing Dex, Lcc was able to colonize the intestine, and stimulated various immune responses in the host.

We evaluated effect of a new synbiotic consisting of probiotic Lcc and its prebiotic dextran on milk production in Holstein dairy cows. In particular, we measured somatic cell counts as a marker for immune-adjuvant activity of the synbiotic. It was demonstrated that milk yield and milk components were improved throughout the year, as compared with that Dex improved milk yield in hot and humid seasons only [22]. Furthermore, cows fed the synbiotic (Group B) consistently showed low somatic cell counts, while the somatic cell counts of cows fed the basic diet only (Group A) were higher. It was found that mastitis rarely occurred in Group B but that it was common in Group A. It has been observed that probiotics bring about a positive change in the bovine intestinal microflora, reduce the incidence of infectious diseases [1, 16, 21, 23], and that somatic cell levels are closely correlated with mastitis in dairy cows, so that high somatic cell counts indicate an increased likelihood of mastitis occurring $[11,18]$. Furthermore, it is said that heat stress in hot seasons increases somatic cell counts [9] and cooling induces relief from stress [19]. Accordingly, it is suggested that administration of probiotics in conjunction with specific prebiotics encourages colonization by probiotics and improves microflora in the intestine, and, as a result, induces higher milk yields and higher levels of desirable milk components. It also stimulates immunity, decreases heat stress, prevents infection by pathogenic bacteria, and reduces the incidence of infectious diseases in the host. Collectively, the actions of the synbiotic appear to have a prophylactic effect and inhibit the development of mastitis.

In this study, the reason milk production was improved 
A

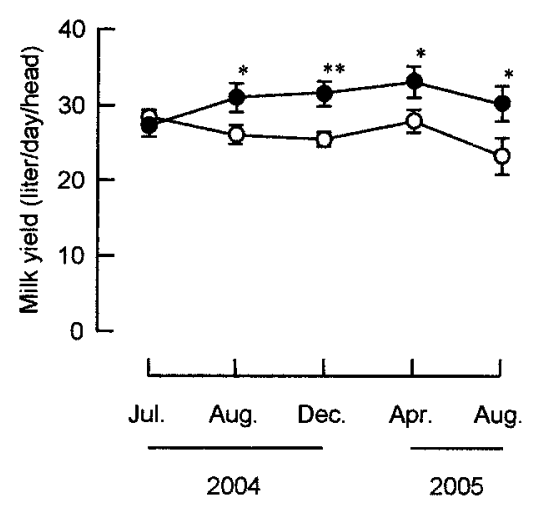

C

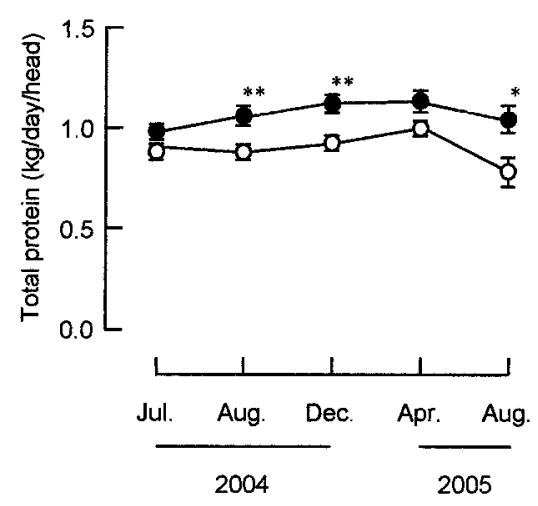

E

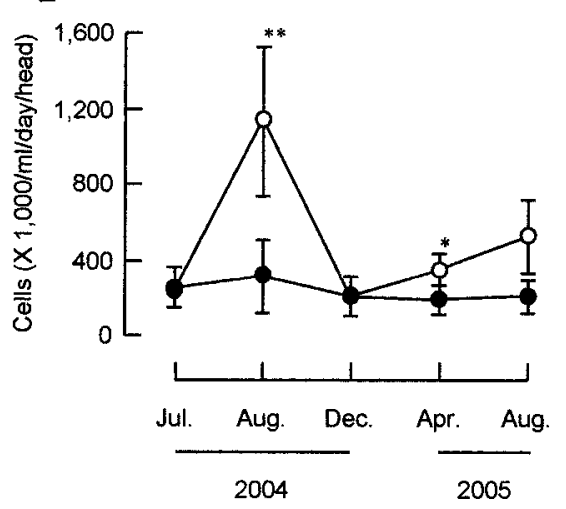

B

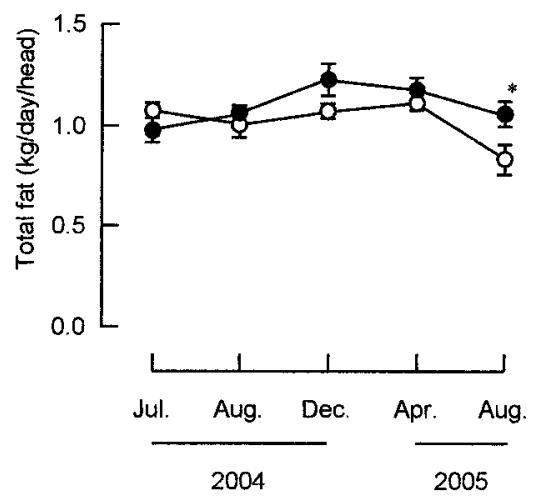

D

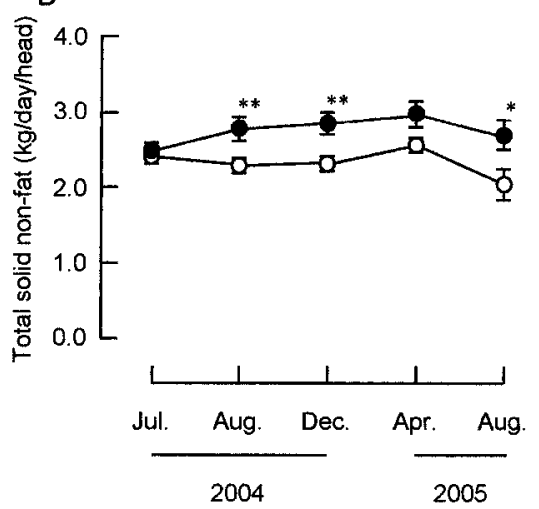

Fig. 1. Effect of mixed feed containing a synbiotic of freeze-dried Lactobacillus casei subsp. casei JCM $1134^{\mathrm{T}}(\mathrm{Lcc})$ and supplemental dextran (Dex) on yields and components of milk. Group A is control (open circle). Group B is test fed the basic diet supplemented with the synbiotic consisting of freeze-dried Lcc and Dex (closed circle). Panel A, B, C, D and E show milk yield, total fat, total protein, total solid-non fat and somatic cell count, respectively. Data are shown as mean \pm standard error of mean (S.E.M.). The mean values were significantly different from Group A $(* p<0.05, * * p<0.01)$.

by the synbiotic appears to be a result of a positive change in the bovine intestinal microflora, a reduction in the incidence of infectious diseases, and a decrease in some forms of stress.

We conclude that this new synbiotic, Lcc in combination with Dex, can improve milk production in Holstein dairy cows throughout the year.

\section{REFERENCES}

1. Brashears, M. M., Galyean, M. L., Loneragan, G. H., Mann, J. E. and Killinger-Mann, K. 2003. J. Food Prot. 66: 748-754.

2. Burgstaller, G., Ferstl, R. and Alps, H. 1984. Züchtungskunde 56: $156-162$.

3. Crawford, J. S., Carver, L., Berger, J. and DANE, G. 1980. Proc. West. Am. Soc. Anim. Sci. 31: 210-212. 
4. Donovan, D. C., Franklin, S. T., Chase, C. C. and Hippen, A. R. 2002. J. Dairy Sci. 85: 947-950.

5. Elam, N. A., Gleghorn, J. F., Rivera, J. D., Galyean, M. L., Defoor, P. J., Brashears, M. M. and Younts-Dahl, S. M. 2003. J. Anim. Sci. 81: 2686-2698.

6. Fukata, T., Sasai, K., Miyamoto, T. and Baba, E. 1999. J. Vet. Med. Sci. 52: 125-128.

7. Fuller, R. 1989. J. Appl. Bacteriol. 66: 365-378.

8. Gibson, G. R. and Roberfroid, M. B. 1995. J. Nutrition. 125: 1401-1412.

9. Green, M. J., Bradley, A. J., Newton, H. and Browne, W. J. 2006. Prev. Vet. Med. 74: 293-308.

10. Hutcheson, D. P., Cole, N. A., Keaton, W., Graham, G., Dunlap, R. and Pittman, K. 1980. Proc. West. Am. Soc. Anim. Sci. 31: $213-215$.

11. Hutton, C. T., Fox, L. K. and Hancock, D. D. 1990. J. Dairy Sci. 73: 1135-1143.

12. Khongdee, S., Chaiyabutr, N., Hinch, G., Markvichitr, K. and Vajrabukka, C. 2006. Internat. J. Biometeorol. 20: 253-257.

13. Ogawa, T., Asai, Y., Yasuda, K. and Sakamoto, H. 2005. Nutr. Res. 25: 295-304.
14. Ogawa, T., Asai, Y., Tamai, R., Makimura, Y., Sakamoto, H., Hashikawa, S. and Yasuda, K. 2005. Clin. Exp. Immunol. 143: 103-109.

15. Ogawa, T., Asai, Y., Sakamoto, H. and Yasuda, K. 2006. Brit. J. Nutr. 95: 430-434.

16. Ohya, T., Marubashi, T. and Ito, H. 2000. J. Vet. Med. Sci. 62: 1151-1155.

17. Sato, Y. 2001. J. Vet. Clin. 48: 653-657.

18. Schukken, Y. H., Vanvliet, J., Vandegeer, D. and Grommers, F. J. 1993. J. Dairy Sci. 76: 2925-2930.

19. Tomaszewski, M. A., de Haan, M. A., Thompson, J. A. and Jordan, E. R. 2005. J. Dairy Sci. 88: 2281-2286.

20. West, J. W. 2003. J. Dairy Sci. 86: 2131-2144.

21. Wren, W. B. 1987. Microbial Genetics Division, Pioneer HiBred international, Des Moinés, lowa, U.S.A.

22. Yasuda, K. and Fukata, T. 2004. J. Vet. Med. Sci. 66: 12871288.

23. Younts-Dahl, S. M., Galyean, M. L., Loneragan, G. H., Elam, N. A. and Brashears, M. M. 2004. J. Food Protect. 67: 889893. 